\title{
Bioactive egg components and their potential uses
}

\author{
M. ANTON ${ }^{1 *}$, F. NAU ${ }^{2}$ and Y. NYS ${ }^{3}$ \\ ${ }^{1}$ INRA BIA, ISD Group, BP 71627, 44316 Nantes cedex 3 - France \\ ${ }^{2}$ UMR 1253 INRA-Agrocampus Rennes, 65 rue de Saint-Brieuc, CS 84215, 35042 Rennes cedex - \\ France \\ ${ }^{3}$ INRA Station de Recherches Avicoles, 37380 Nouzilly - France \\ *anton@nantes.inra.fr
}

Key words: egg; molecules; biological properties

\begin{abstract}
Hen egg plays a crucial role in the development of embryonic bird. It serves first as source of energy and nutriments of high digestibility and, second, protects embryonic bird against external aggressions. The unique structure of egg with yolk containing the embryo surrounded by albumen and shell as physical barriers is the first element of this protection. The second one consists in the peculiar composition of yolk, albumen and shell with many molecules possessing elevated biological properties. Thus, these molecules represent a major source of active principles usable by medical, pharmaceutical, cosmetical, nutraceutical and biotechnological industries. In this review we will focus particularly on nutritional, health, and biotechnological activities of egg molecules and on the approaches, which are proposed by European research groups, to exploit this bioactive potential.
\end{abstract}

\section{Introduction}

Hen egg possesses an excellent nutritive value and constitutes a traditional food used in many basic and formulated preparations. Besides its important reserve of highly digestible proteins, lipids, vitamins and minerals, egg contains molecules with numerous health promoting and biotechnological properties. Its original role as an embryonic chamber supposes that it contains many components essential for life. These components has been analysed and studied for several years. Some strategies to prepare and/or use them for biological applications have been developed. The aim of this review is to make an update on the bioactive compounds of hen egg with a particular focus on nutritional, health and biotechnological activities. Furthermore, this review will insist on the new approaches developed by research groups and particularly European groups collaborating on the COST action 923 (http://www.sci.utu.fi/biokemia/cost923/).

\section{Nutritional activities}

LIPIDS

Lipids are the primary components of egg yolk (about $65 \%$ of the dry matter). They are composed of triglycerides $(65 \%)$, phospholipids $(29 \%)$, out of which $86 \%$ are phosphatidylcholine and $14 \%$ phosphatidylethanolamine, cholesterol $(5 \%)$, and free fatty acids $(<1 \%)$. The fatty acid composition of yolk from hens fed with a corn-soybean diet, corresponds to $35 \%$ saturated fatty acids (SFA), $45 \%$ monounsaturated fatty acids (MUFA) and $20 \%$ polyunsaturated fatty acids (PUFA) (Anton and Gandemer, 1997). Consequently yolk is a plentiful source of lipids out of which some are particularly suitable for nutrition or health.

Particularly, omega 3 fatty acids $(\omega 3)$ are considered to be an essential nutrient for brain function and visual acuity in humans (Maki et al., 2003). Eicosapentaenoic acid (EPA) and docosahexaenoic acid (DHA) are the main $\omega 3$ fatty acids. They are particularly useful for pregnant and nursing mothers for optimising growth of their infants especially as breast milk is currently low in $\omega 3$ due to the modern diet of mothers.

Phosphatidylcholine is an amphiphilic lipid containing $\omega 3$ fatty acids as non polar part, and choline as polar part. Choline is an important nutrient in brain development, liver function, and cancer prevention (Gutierrez et al., 1997). Choline is routinely added to commercial infant formulations as an 
essential nutrient. Consumption of phosphatidylcholine increases plasma and brain choline levels and accelerates neuronal acetylcholine synthesis. Yolk phospholipids are naturally rich in phosphatidylcholine ( $86 \%$ of the total phospholipids), which is more than three-fold higher than natural soy phospholipids. It has been demonstrated that consumption of yolk phospholipids tends to alleviate the symptoms of Alzheimer disease (Juneja, 1997).

\section{VITAMINS AND MINERALS}

Generally, egg is an excellent source of vitamins, and particularly of vitamins A, D, E, K, and B1, B2, B9, B12. Vitamins $A, D$ and $E$, and $\mathrm{K}$, and are liposoluble and consequently deposited in the yolk. Whereas vitamins B1 (thiamin) and B12 (cyanobalamine), are hydrosoluble and situated in albumen. B2 (riboflavin) and B9 (folate) are hydrosoluble and equally distributed in yolk and albumen. Egg yolk is also a suitable source of iron and phosphorus.

\section{POSSIBLE DEVELOPMENTS}

A current strategy consists to modify the composition of lipids, and to improve the content of vitamins and minerals, in view to ameliorate the nutritional value of eggs by enrichment on some specific nutritive compounds. As an example, it is known that egg yolk can be enriched in $\omega 3$ fatty acids by feeding hens with high level of $\omega 3$ fatty acids: fish oil (menhaden, herring or tuna) or flax seeds (Leskanish and Noble, 1997). While eggs produced by hens feed corn-soybean diets contain $0.3 \% \omega 3$ fatty acids, those produced by hens on specially formulated feed contain $2.5 \% \omega 3$ fatty acids $(7-10$ times higher than the former). The resulting $\omega 6: \omega 3$ ratio of the omega eggs $(6.5: 1)$, corresponds to the ideal ratio recommended for human and therefore has potential benefits for health.

We can also envisage to focus on vitamins which are marginally supplied in the western diet (vitamin A, D and B9) (Mattila et al., 2004). The key parameters are to make enrichment of hens diet with these vitamins, to check the effective increase on their concentration in eggs, to measure their bioavailability in animals and humans, and to decree about the physiological enhancement on animals and humans. Parallel approaches can be envisaged with minerals using the capacity of some proteins to fix some cations and trying to propose either egg enriched on some minerals, or some formulated food with egg components encapsulating some minerals (see later).

The global approach for improving nutritional value of egg ( $\omega 3$ fatty acids, vitamins, minerals) by hen feed is called "enhanced egg". It consists in giving information on the public, validating the nutritional values of the eggs and their benefits in human health, and standardising the production methods (Yannakopoulos, 2003).

\section{Health activities}

\section{ANTIMICROBIAL ACTIVITY}

Lysozyme from egg albumen catalyses the hydrolysis of the $\mathrm{B}-(1-4)$ linkage between $\mathrm{N}$-acetylmuramic acid and $\mathrm{N}$-acetylglucosamine of bacterial peptidoglycan, which is the structural component of the Gram-positive bacterial cell walls. Lysozyme is particularly effective against oral affections, due to the cariogenic bacteria Streptococcus mutans or against periodontitis-associated bacteria (Tenovuo et al., 1991). Given orally, lysozyme alleviates the reduced endogenous production of saliva lysozyme during parodontopathy (Sava, 1996).

Lysozyme is also largely used as a food preservative. It shows high activity against mesophilic and thermophilic spore-former bacteria such as Bacillus staerothermophilus, Clostridium thermosaccharolyticum and Clostridium tyrobutyricum (Johnson, 1994). It is used in cheese to prevent contamination because of the absence of inhibition on starter and secondary cultures required for the ripening of the cheeses. Lysozyme also prevents the growth of pathogenic bacteria on refrigerated foods: Listeria monocytogenes, Clostridium botulinum, Clostridium jejuni and Yersinia enterocolitica are susceptible to the lytic activity of lysozyme (Johnson, 1994).

Ovotransferrin from egg albumen inhibits Gram-negative bacteria by depriving bacteria of iron that is essential for their growth (Lock and Board, 1992). Ovotransferrin has therefore been proposed in infant nutrition and for the treatment of infants with acute diarrhoeas (del Giacco et al., 1985). Recently, the iron chelating activity of ovotransferrin has been shown to increase the stimulation by an inhibitor of AMPc ß-lactamase (Syn 2190) of some antibiotics which are efficient against most ß- 
lactamase-producing bacteria (Babini and Livermore, 2000). Ovotransferrin therefore appears as a key factor for drug associations able to overcome the cephalosporin resistance.

Valenti et al. $(1983,1986)$ and Baron (1998) suggest that ovotransferrin antibacterial activity can result from a direct effect on the membranes of Candida albicans or Salmonella enteritidis. This hypothesis was confirmed for OTAP-92, a cationic peptidic fragment of hen ovotransferrin which possesses a unique structural motif similar to the insect defensins. This domain is able to cross the bacterial membrane by a self-promoted uptake, and working in synergy with the polycationic nature of OTAP-92, kills bacteria by damaging the biological function of its cytoplasmic membrane (Ibrahim et al., 2000). Its strong bactericidal activity against both Gram-positive (Staphylococcus aureus) and Gram-negative (Escherichia coli) strains bring the authors to envisage therapeutical applications for this natural peptide.

Interestingly, some proteins initially known for their contribution to the mechanical and microstructural properties of the shell have also antibacterial activities (Nys et al., 2004). These proteins are specifically and sequentially expressed in the uterus and are now subjected to investigations.

\section{ANTIVIRAL ACTIVITY}

Given orally or after local application, lysozyme from egg albumen is effective for a wide range of viral skin diseases: herpetic lesions, verruca vulgaris and plantaris, aphtous stomatitis, polymorphous exudative erythema, molluscum contagiosum ... (de Douder and Morias, 1974). Moreover, when combined with specific immunotherapy, lysozyme cures viral sinusitis or bronchitis (Gavrilenko et al., 1992). The antiviral action of lysozyme has partly been explained by its role on the precipitation of viral particles and by its immune-enhancing action on the host together with its interaction with the pathogens (Sava, 1996). Kijowski and Lesnierowski (1999) have proposed some protocols to modify thermally of chemically lysozyme to increase its antiviral activity.

The anti-hemagglutination activity of the fibriform glycoprotein ovomucin shown initially against swine influenza virus has been confirmed by Tsuge et al. (1996) against bovine rotavirus and hen Newcastle disease virus.

\section{ANTIGENIC ACTIVITY}

The antibody activity of egg yolk is due to $\gamma$-livetins, named IgY: Yolk Immunoglobulin (Leslie and Clem, 1969). IgY are synthesised in the hen serum and then transferred into yolk to immunise the embryonic chicken. $\gamma$-livetin is a glycoprotein that contains heavy chains $(60-70 \mathrm{kDa})$ and light chains $(22 \mathrm{kDa})$ and represents about $3 \%$ of yolk dry matter.

One hen generally lays about 290 eggs per year which represents $5,000 \mathrm{~g}$ of yolk. The level of IgY in yolk ranges from $9 \mathrm{mg} / \mathrm{ml}$ to $25 \mathrm{mg} / \mathrm{ml}$ (Rose et al., 1974). Consequently, one hen can produce about $60 \mathrm{~g}$ of IgY per year (Nakai et al., 1994). The production of IgY by hens is thirty times greater than that by rabbits. Egg yolk is then a potential source of antibodies for humans because it can be produced on a large-scale.

Furthermore, various types of $\lg Y$ can be overproduced in egg yolk by immunising hens with specific antigens: proteins, bacteria, viruses, parasites, toxins. Hen antibody production is a good alternative to conventional mammal antibody production because it improves the welfare of animals due to the non-invasive method of egg collection and because of the fast and simple IgY isolation from egg yolk (Tini et al., 2002).

Numerous applications of hen IgY antibodies have been evaluated in human against dental plaque formation or against rotavirus diarrhoea in trout, to protect against Yersinia rucckeri, or in swine to control bacterial respiratory disease (Shin et al., 2001). Furthermore hen IgY antibodies against specific proteins can be raised for biological quantification such as detection by ELISA of fungi (Vohringer and Sander, 2001).

New applications are currently attempted (Schade and Schwagele, 2004). The lgY-technology is a method used for production of polyclonal antibody (Ab) in chicken (Schade et al. 1996). Since the antibody is non-invasively obtained this method belongs to the so called alternative methods and thus follows a principal European guideline concerning animal protection. Besides of the aspect of animal protection due to the non-invasive Ab sampling, there is the advantage of a very high quantity of $A b$ which can be obtained from one chicken (until $60 \mathrm{~g}$ total $\mathrm{lg}$ from one hen per year). That fact makes the IgY-technology of great interest for research fields which need large amount of $A b$ for prophylactical or therapeutical purposes in human and veterinary medicine. 


\section{ANTIHYPERTENSIVE ACTIVITY}

Two peptides derived from ovalbumin are effective in preventing hypertension. The first one, named ovokinin, was purified from a peptic digest of ovalbumin (residues 358-365). It is a weak bradykinin B1 agonist peptide, which lowers the systolic blood pressure in spontaneously hypertensive rats when administered as an emulsion in egg yolk (Fujita et al., 1995). The second one, ovokinin(2-7) is obtained by chymotryptic digestion of ovalbumin (residues 359-364; Matoba et al., 1999). When orally administered, this vasorelaxing peptide reduces the blood pressure of spontaneously hypertensive rats in a dose-dependent manner. Ovokinin(2-7) has also been used for designing peptide derivatives with activity comparable to that of synthetic anti-hypertensive drugs clinically used (Matoba et al., 2001). The relaxation due to ovokinin(2-7) is mediated by nitric oxide and an unknown receptor.

Recently, Miguel et al. (2004) have obtained and characterised peptides from egg albumen possessing inhibitory effect of enzyme of conversion of angiotensin (ECA) responsible for physiological mechanism conducting to hypertension. Pepsin is very efficient to obtain active (ICA and antioxidant) peptides (molecular weight lower than $3000 \mathrm{Da}$ ) from egg albumen. These peptides diminish significantly the blood pressure of spontaneous hypertensive rats.

A very innovative approach consists in selecting peptides in silico by specific softwares able to handle multiple peptide sequences, to screen for motifs and to quantify the theoretical total activity (Vermeissen et al., 2004). These authors have constructed a database containing more than 500 peptide sequences and their antihypertensive activities. In parallel, digestion simulations, and the inhibitory activity of the digests on ECA are determined in vitro.

\section{ANTICANCER TREATMENT}

Some findings show the potential use of avidin from egg albumen to reinforce some anticancer treatments (Gasparri et al., 1999). Tumour avidination potentiates the antitumour activity of biotin-TNF (tumour necrosis factor $\alpha$ ), used as a local or loco regional anticancer drug. Such a pretargeting process increased the binding and persistence of biotin-TNF on the surface of tumour cells in vivo. Furthermore, these authors suggest that potentialisation of avidin as antitumour may involve changes in host-tumour relationships and/or host-mediated antitumour responses. Therefore, pretargeting with avidin could be a realistic possibility to improve the therapeutic index of some anticancer drugs.

\section{IMMUNE MODULATION AND ACTIVATION}

The development of bacterial drug-resistance encourages the identification of efficient immunostimulants to improve the host defence mechanisms. An active egg albumen product was obtained by fermentation with Saccharomyces cerevisiae and spray drying (Araki et al., 1992). Its oral administration improves the nonspecific phagocytic activity of neutrophils in weanling piglets and in calves (Nakagawa et al., 1993). It should therefore enhance the host defence mechanism against infectious diseases.

Lysozyme from egg albumen affects also some components of the immune system of the host which may explain part of its reported activity: reduction in thymus hyperplasia, activation of host immunity against subchronic enterocolitis, against child viral hepatitis and polyomyelitis, increase in absolute granulocyte counts after antiblastic therapy, modification of the lymphocyte responses. This last property suggests that lysozyme is of interest in cancer treatments, for recovering from immune suppression due to anticancer therapy (Sava, 1996). Lysozyme may also control the imbalances of immunity during autoimmune diseases. These activities were mainly attributed to human lysozyme, but hen egg white lysozyme has been shown to be effective on human immuno-competent cells. Lysozyme is generally efficient even after oral administration (Sava, 1996).

Family 2 cystatins, including egg cystatin, affect the host's immune response through the cytokine network. Chicken cystatin stimulates nitric oxide production from mouse peritoneal macrophages (Verdot et al., 1996) and interleukine production by human gingival fibroblast cell lines and murine splenocytes at physiological concentrations (Kato et al., 2000). It could then be envisaged for the host defence against infectious or parasitic agents, as well as against cancer cell metastasis (Nakai, 2000).

\section{ANTIOXIDANT ACTIVITY}

The capacity of metal chelation of phosvitin from yolk gives to this protein remarkable antioxidant potentialities. Phosvitin contains about 110 phosphoseryl residues $(50 \%$ of its amino acids), responsible for its iron binding capacity (Itoh et al., 1983). Phosvitin inhibits phospholipid oxidation 
catalysed by $\mathrm{Cu}^{2+}$ and even more by $\mathrm{Fe}^{2+}$. Phosvitin is efficient up to a $\mathrm{Fe}^{2+}$ to phosvitin ratio of $30: 1$, whereas this maximal ratio is $1: 1$ with $\mathrm{Cu}^{2+}$ (Lu and Baker, 1986). However, phosvitin loses its antioxidant capacity when oxidation is catalysed by haeminic iron. It is likely that haeminic iron can not be chelated by phosvitin because it is buried into a porphyrin structure which limits the interaction of iron and phosphoseryl residues of phosvitin.

Castellani et al. (2004) have established that the optimal conditions for iron fixation $(115 \mu \mathrm{g}$ iron $/ \mathrm{mg}$ protein) are at $\mathrm{pH} 6.5$ and $\mathrm{NaCl}$ level of $0.15 \mathrm{M}$. When $\mathrm{pH}$ is fixed at 3.5, the chelation of iron is inhibited by protonation of the phosphate groups and by conformational changes in the protein. However, acidification of the solution after iron fixation does not promote the release of iron.

Pasteurisation does not affect the iron-binding capacity of phosvitin, or its antioxidant property (Lu and Baker, 1986). Furthermore, heating phosvitin at $110^{\circ} \mathrm{C}$ for 20 and $40 \mathrm{~min}$ does not cause the release of iron bound to phosvitin. Consequently, phosvitin could be a very important natural food antioxidant.

\section{Biotechnological activity}

\section{DIAGNOSTIC APPLICATION}

The complex avidin-biotin is used in a very wide spectrum of biochemical or diagnostic applications because of the lack of interaction between the carboxy-containing side chain of biotin and avidin. This site can be modified chemically and attached to a wide variety of biologically active material, without altering the binding of avidin with the other moiety of biotin derivative or conjugate. In addition, avidin can be derivatised with various molecules or probes (Bayer and Wilchek, 1994).

In the early 1980s, streptavidin (an avidin-like protein produced by Streptomyces strains) was preferred to egg avidin, despite its high cost, because of its reduced levels of nonspecific binding and its low background staining. Its use was later questioned because of equivocal interactions between the bacterial protein and unidentified macromolecular components in numerous experimental systems. Numerous conjugates, complexes, and derivatives, derived from avidin and streptavidin are commercially available, with characteristics specifically suitable for each application (Bayer and Wilchek, 1994).

Egg antibodies (IgY from yolk) are promising for use in immunoassays (Schade, 2004) to quantify toxins or pathogenic viruses for example. Their use as functional tool in pharmaceutical application is clearly explored.

\section{CRYOPROTECTIVE ACTIVITY}

Techniques for artificial insemination are largely used for domestic animals. Freezing spermatozoa for storage is a prerequisite for artificial insemination but leads to the formation of ice crystals constituted of pure water that can disrupt the spermatozoa membrane by mechanical or osmotic effects. Consequently, after ejaculation, spermatozoa are rapidly mixed with a cryoprotective medium called extender before freezing or cooling.

Egg yolk is commonly used as a protectant in semen extenders to preserve mammalian spermatozoa against cold chock but the precise mechanism by which egg yolk acts is unknown. It has been proposed that the low-density fraction of yolk, mainly composed of low-density lipoproteins (LDL) from yolk, could be responsible for the resistance against cold shock and for the improvement of motility of spermatozoa after storage. Foulkes (1977), and Graham and Foote (1987), suggested that LDL could adhere to cell membranes during the freeze-thaw process, thus preserving spermatozoa membranes. Phospholipids, which surround the lipid core of triglycerides and cholesterol, play an essential role in the stability of the LDL structure because association forces are essentially hydrophobic (Cook and Martin, 1969).

Moussa et al. (2002) have developed an easy method to extract LDL from egg yolk. This extraction method reaches $97 \%$ purity and about $67 \%$ yield, and is easily reproducible on an industrial scale. This purified LDL had an improved efficiency on the spermatozoa motility and survival compared with commercial extenders when present at $8 \%$ in the extender for bull semen. However, further work is needed for evaluating its usefulness for other species and for elucidating the cryoprotective mechanism of LDL. 


\section{MICROENCAPSULATION SYSTEMS}

Phospholipids form yolk could serve as encapsulation systems (liposomes, double emulsions) and proteins from albumen as microspheres and microcapsules to entrap hydrophobic (liposomes, microcapsules) or hydrophilic (microspheres) compounds. More precisely, in human and in animal nutrition, liposomes could be used to increase bioavailability of hydrophobic vitamins like vitamin E. The functionality of such liposomes has been tested in rats, considered as a good model form human digestion/absorption processes. (Cansell et al., 2003).Other applications are also envisaged for microspheres such as prevention of dust formation, masking off-flavour, and prevention from degradation by hydrolytic enzymes (Vingerhoeds, 2004). We can also envisage to entrap minerals like iron or calcium by some egg proteins (ovotransferrin, phosvitin, ...) and to construct a dispersed food system enriched on these minerals.

\section{BIOPLASTICS}

The importance of new biodegradable biomaterials is not only that they help to reduce waste materials but they could help to preserve petroleum reserves by substituting synthetic polymers (De Graaf and Kolster 1998). A plasticizer is often required to overcome film brittleness and helping to avoid chipping and cracking of films during subsequent handling and storage. Plasticizers are molecules with low molecular weight, low volatility, which modify the three-dimensional structure of proteins. Proteins coming from egg albumen could be excellent candidates to obtain a biodegradable plastic material with suitable mechanical properties to be a potential substitute of synthetic polymers in certain applications. (Jerez et al., 2005.)

\section{Conclusion}

This review shows that egg (yolk, albumen and shell) contain many biologically active molecules with very specific properties applicable on nutrition, health and biotechnology. Different approaches exist including the enrichment of egg on some health and nutrition benefiting components, the extraction and the use of the components directly for their activities, or the use of egg components as medium actor of biotechnological processes. In some of this cases extraction and purification strategies are to be envisaged and developed at laboratory, pilot and industrial scale (Croguennec et al., 2001, Aro, 2003 ). Minor egg components are still to be identified thanks to international databanks, mass spectrometry, and molecular biology (Nau et al., 2003, 2005). Whatever the approach, the production and identification of molecules of interest need major research efforts in egg biochemistry, molecular biology, technology and in clinical trials for exploiting the promising molecules within eggs.

\section{References}

Anton M., Gandemer G. (1997) Composition, solubility and emulsifying properties of granules and plasma of hen egg yolk. J. Food Sci., 62 (3): 484-487.

Araki S., Suzuki M., Fujimoto M. (1992) Enhanced resistance to bacterial infections in mice by oral administrating of an active egg white product. J. Vet. Med. Sci., 54 (5): 1055-1056.

Aro H. (2003). Simultaneous pilot-scale extraction and precipitation of egg yolk phospholipids using supercritical techniques. Xth European Symposium on the Quality of Eggs and Egg products, Ploufragan, $23-26^{\text {th }}$ sept.

Babini G.S., Livermore D.M. (2000) Effect of conalbumin on the activity of Syn2190, a 1,5 dihydroxy4-pyridon monobactam inhibitor of AmpC ß-lactamases. J. Antimicrobial Chemotherapy, 45: 105109.

Baron F. (1998) Etude du comportement de Salmonella enteritidis dans le blanc d'œuf. PhD thesis, ENSA Rennes, France, $120 \mathrm{p}$.

Bayer E.A., Wilchek M. (1994) Modified avidins for application in avidin-biotin technology: an improvement on nature. In Egg uses and processing technologies, new developments, Sim and Nakai Eds, CAB Int., Oxon, UK, pp158-176.

Cansell M., Nacka F., Combe N. (2003). Marine lipid-based liposomes increase in vivo fatty acid bioavailability, Lipids, 38, 551-559

Castellani O., Guérin-Dubiard C., David-Briand E., Anton M. (2004). Influence of physico-chemical conditions and technological treatment on the iron binding capacity of hen egg phosvitin. Food Chem., 85, 569-577. 
Cook WH, Martin WG. (1969) Egg lipoproteins. In . E Tria, AM Scanu (eds): Structural and Functional Aspects of Lipoproteins in Living Systems. New York: Academic Press, pp 579-615.

Croguennec T, Nau F, Pézennec S, Piot M, Brulé G (2001) Two-step chromatographic procedure for the preparation of hen egg white ovotransferrin. Eur. Food Res. Technol., 212: 296-301.

Jerez A., Partal P., Martinez I., Gallegos C., Guerrero A. (2005). Rheology and processing of gluten based bioplastics. Biochem. Eng. J., in press.

De Douder C., Morias J. (1974) On lysozyme therapy. II. Topical treatment of viral and non viral cutaneous lesions with lysozyme ointment. Medickon, 3: 21-22.

De Graaf L. A., Kolster P. (1998) Macromol. Symp. 127 51-58

del Giacco G.S., Leone A.L., Ferlazzo A. (1985) Total IgE in newborns treated prophylactically with conalbumin. Int. J. Tiss. Reac., 7: 535-537.

Foulkes JA. (1977). The separation of lipoproteins from egg yolk and their effect on the motility and integrity of bovine spermatozoa. J. Reprod. Fertil., 49: 277-284.

Fujita H., Sasaki R., Yoshikawa M. (1995) Potentiation of the antihypertensive activity of orally administered ovokinin, a vasorelaxing peptide derived from ovalbumin, by emulsification in egg phosphatidyl-choline. Biosci. Biotech. Biochem., 59 (12): 2344-2345.

Gasparri A., Moro M., Curnis F., Sacchi A., Pagano S., Veglia F., Casorati G., Siccardi A.G., Dellabona P., Corti A. (1999) Tumor pretargeting with avidin improves the therapeutic index of biotinylated tumor necrosis factor a in mouse models. Cancer Res., 59: 2917-2923.

Gavrilenko T.I., Siurin S.A., Lolaeva L.T., Sauchenko V.M. (1992) The characteristics of lysozyme and carbenicillin action on the clinico-immunological status of patients with chronic bronchitis. Vrach. Delo, 8: 42-45.

Graham J.K., Foote R.H. (1987) Effect of several lipids. fatty acyl chain length and degree of unsaturation on the motility of bull spermatozoa after cold shock and freezing. Cryobiol., 24:42-52.

Gutierrez M.A., Takahashi H., Juneja L.R. (1997). Nutritive evaluation of hen eggs, In: Yamamoto T., Juneja L., Hatta H., Kim M. (Eds.), CRC Press, Boca Raton (USA) pp. 25-35.

Ibrahim H.R., Sugimoto Y., Aoki T. (2000) Ovotransferrin antimicrobial peptide (OTAP-92) kills bacteria through a membrane damage mechanism. Biochim. Biophys. Acta, 1523: 196-205.

Itoh T., Abe Y., Adachi S. (1983) Comparative studies on the - and -phosvitin from hen's egg yolk. J. Food Sci., 48: 1755-1757.

Johnson E.A. (1994) Egg white lysozyme as a preservative for use in foods. In Egg uses and processing technologies, new developments, Sim and Nakai Eds, CAB Int., Oxon, UK, pp 177-191.

Juneja L.R. (1997) Egg yolk lipids, In: Yamamoto T., Juneja L., Hatta H., Kim M. (Eds.), CRC Press, Boca Raton (USA) pp. 73-98.

Kato T., Imatani T., Miura T., Minaguchi K., Saitoh E., Okuda K. (2000) Cytokine-inducing activity of family 2 cystatins. Biol. Chem., 381: 1143-1147.

Kijowski J., Lesnierowski G. (1999) Separation, polymer formation and antibacterial activity of lysozym. Polish J. Food Nutr. Sci., 49: 3-16.

Leskanish C.O., Noble R.C. (1997) Manipulation of the n-3 polyunsaturated fatty acid composition of avian egg and meat. World's poultry Sci. J., 53: 253-264.

Leslie G.A., Clem L.W. (1969) Phylogeny of immunoglobulin structure and function. III. Immunoglobulin of the chicken. J. Exp. Med., 130: 1337-1945.

Lock J.L., Board R.G. (1992) Persistence of contamination of hen's egg albumen in vitro with Salmonella serotypes. Epidemiol. Infect., 108: 389-396.

Lu CL., Baker RC. (1986) Characteristics of egg yolk phosvitin as an antioxidant for inhibiting metalcatalyzed phospholipid oxidation. Poultry Sci., 65: 2065-2073.

Maki K.C., Van Elswyk M.E., McCarthy D., Seeley M.A., Veith P.E., Hess S.P., Ingram K.A., Halvorson J.J., Calaguas E.M., Davidson M.H., (2003). Lipid responses in mildly hypertriglyceridemic men and women to consumption of docosahexaenoic acid-enriched eggs. Int. J. Vitam. Nutr. Res., 73, 357-368.

Mattila P., Lehikoinen K., Kiiskinen T., Piironen V., (1999). Cholecalciferol and 25hydroxycholecalciferol content of chicken egg yolk as affected by the cholecalciferol content of feed. J. Agric. Food Chem., 47, 4089-4092.

Matoba N., Usui H., Fujita H., Yoshikawa M. (1999) A novel anti-hypertensive peptide derived from ovalbumin induces nitric oxide-mediated vasorelaxation in an isolated SHR mesenteric artery. FEBS Letters, 452: 181-184.

Matoba N., Yamada Y., Usui H., Nakagiri R., Yoshikawa M. (2001) Designing potent derivatives of ovokinin(2-7), an anti-hypertensive peptide derived from ovalbumin. Biosci Biotechnol Biochem. 2001, 65(3):736-739. 
Miguel M., Recio J.A., Gomez-Ruiz A., Ramos M., Lopez-Fandino R. (2004) Angiotensin Iconverting enzyme inhibitory activity of peptides derived from egg white proteins by enzymatic hydrolysis. J. Food protect., 67: 1914-1920.

Moussa M., Martinet V., Trimeche A., Tainturier D. and Anton M. (2002) Low density lipoproteins extracted from hen egg yolk by an easy method: Cryoprotective effect on freeze-thaw bull semen. Theriogenol., 57: 1695-1706.

Nakagawa J., Osame S., Ichijo S., Araki S. Kimura M. (1993) Effects of active egg white product on neutrophil function in calves. J. Vet. Med. Sci., 55 (2): 259-263.

Nakai S. (2000) Molecular modification of egg proteins for functional improvement. In Egg nutrition and biotechnology, Sim, Nakai and Guenter Eds, CAB Int., Oxon, UK, pp 205-217.

Nakai S., Li-Chan E., Lo K. V. (1994) Separation of yolk immunoglobulin, In: Egg Uses \& Processing Technologies. New Developments. Sim J.S., Nakai S. (Eds.), CAB International, Oxon (UK), pp. 94105.

Nau F, Guérin-Dubiard C, Désert C, Gautron J, Bouton S, Gribonval J, Lagarrigue S (2003) Cloning and characterization of HEP21, a new member of the uPAR/Ly6 protein superfamily predominantly expressed in hen egg white. Poultry Sci., 82: 242-250.

Nau F, Pasco M, Désert C, Mollé D, Croguennec T, Guérin-Dubiard C (2005) Identification and characterization of ovalbumin gene $Y$ in hen egg white. J. Agric. Food Chem., 53: 2158-2163.

Nys Y., Gautron J., Garcia-Ruiz J.M., Hincke M.T. (2004). Avian eggshell mineralization: biochemical and functional characterization of matrix proteins. Comptes Rendus Palevo, 3: 549562.

Rose M.E., Orlans E., Buttress, N. (1974) Immunoglobulin classes in the hen's egg: their segregation in yolk and white. Eur. J. Immunol. 4: 521-523.

Sava G. (1996) Pharmacological aspects and therapeutic applications of lysozymes. EXS, 75: 433449.

Schade R, Staak C, Hendriksen C, Erhard M, Hugl H, Koch G, Larsson A, Pollmann W, Van Regenmortel M, Rijke E, Spielmann H, Steinbusch H, Straughan D (1996) The production of avian (egg yolk) antibodies: IgY. ECVAM Workshop 21. ATLA 24, 925-934.

Schade R., Schwägele F. (2004) Production of neutralizing $\lg Y$ antibody against toxins and hazardous viruses. COST 923 workshop, 38.

Shin N., Kim J., Choi I. And Yoo H. (2001). Control of swine respiratory disease using egg yolk antibodies. Kor. J. Vet Res.41: 197-202.

Tenovuo J., Lumikari M., Soukka T. (1991) Salivary lysozyme, lactoferrin and peroxidases: antibacterial effects on cariogenic bacteria and clinical applications in preventive denstistry. Proc. Finn. Dent. Soc., 87: 197-208.

Tini M., Jewell U.R., Camanish G., Chilov D., Gassmann M. (2002). Generation and application of chicken egg-yolk antibodies. Comp. Biochem. Physiol. A 131: 569-574.

Tsuge Y., Shimoyamada M., Watanabe K. (1996) Differences in hemagglutination inhibition activity against bovine rotavirus and hen Newcastle disease virus based on the subunits in hen egg white ovomucin. Biosci. Biotech. Biochem., 60 (9): 1505-1506.

Valenti P., Antonini G., Von Hunolstein C., Visca P., Orsi N., Antonini E. (1983) Studies on the antimicrobial activity of ovotransferrin. Int. J. Tiss. Reac., 5 (1): 97-105.

Valenti P., Visca P., Antonini G., Orsi N. (1986) Interaction between lactoferrin and ovotransferrin and Candida cells. FEMS Microbiol. Lett., 33: 271-275.

Verdot L., Lalmanach G., Vercruysse V., Hartmann S., Lucius R., Hoebeke J., Gauthier F., Vray B. (1996) Cystatins upregulated nitric oxide release from interferon-g-activated mouse peritoneal macrophages. J. Biol. Chem., 271: 28077-28081.

Vermeirssen, van der Bent A., van Camp, van Amerongen A., Verstraete . (2004) . A quantitative in silico analysis calculates the angiotensin I converting enzyme (ACE) inhibitory activity in pea and whey protein digests. Biochim., 86: 231-239.

Vingerhoeds M. (2004). Proteins: natural and flexible materials for microencapsulation. Polymers: Delivering new Performances to Microcapsules, Liège, Belgium - November 9-10.

Vohringer C., Sander E. (2001). Comparison of antibodies in chicken egg yolk (IgY) and rabbit (IgG) for quantitative strain detection of Colletotrichum falcatum and Fusarium subglutinans with Elisa. Zeitsch. Pflanzenkrankheiten Plflanzenschhutz, 108: 39-48

Yannakopoulos, A., Tserveni-Gousi, A., Dimovelis, P., Fortomaris, P., Sossidou E. (2003). Poultry production in mountain regions in Greece. International Symposium" Animal Production and Natural Resources Utilisation in the Mediterranean Mountain areas. June 5-7, Ioannina, Greece. 